\title{
Hubungan Budaya Organisasi dan Supervisi Dengan Efektivitas Kerja Kepala Sekolah Dasar Negeri di Kota Mataram
}

\author{
Muhamad Suhardi', M. Ary Irawan ${ }^{2}$ \\ 1,2 Administrasi Pendidikan, Fakultas Ilmu Pendidikan dan Psikologi, UNDIKMA \\ Coresponding Autor: ardhysmart7@gmail.com
}

\begin{abstract}
Abstrak: Tujuan dari penelitian ini adalah untuk mengetahui hubungan budaya organisasi dan pengawasan terhadap efektivitas organisasi kepala sekolah dasar negeri di Kota Mataram. Metodologi penelitian adalah survei yang dipilih dengan teknik simple random sampling. Analisis dan interpretasi data menunjukkan bahwa (1) budaya organisasi memiliki hubungan langsung positif dalam efektivitas organisasi, (2) pengawasan memiliki efek hubungan positif dalam efektivitas organisasi, (3) budaya organisasi dan pengawasan bersama-sama memiliki hubungan langsung positif dalam organisasi efektivitas.
\end{abstract}

Kata kunci: budaya organisasi, pengawasan, efektivitas organisasi.

\section{Relationship between Organizational Culture and Supervision with Work Effectiveness of Principals of Public Elementary Schools in Mataram City}

\author{
Muhamad Suhardi ${ }^{1}$, M. Ary Irawan ${ }^{2}$ \\ ${ }_{1,2}$ Educational Administration, Faculty of Education and Psychology, UNDIKMA \\ ardhysmart7@gmail.com
}

\begin{abstract}
The purpose of this research is to determine the relation of organizational culture and supervision on organizational effectiveness head of state primary school in the Mataram City. The research methodology was survey which were selected by simple random sampling technique. Analysis and interpretation of the data indicate that (1) organizational culture has a positive direct relation in organizational effectiveness, (2) supervision has a positive relation effect in organizational effectiveness, (3) organizational culture and supervision together has a positive direct relation in organizational effectiveness.
\end{abstract}

Keywords: organizational culture, supervision, organizational effectiveness.

\section{A. PENDAHULUAN}

Pendidikan adalah usaha sadar dan terencana untuk mewujudkan suasana belajar dan proses pembelajaran agar peserta didik secara aktif mengembangkan potensi dirinya untuk memiliki kekuatan spiritual keagamaan, pengendalian diri, kepribadian, kecerdasan, akhlak mulia, serta keterampilan yang diperlukan dirinya, masyarakat, bangsa, dan negara. Pemerintah memfasilitasi pendidikan tersebut melalui program Wajib Belajar untuk tingkat SD dan SMP. Program ini merupakan program pendidikan minimal yang harus diikuti oleh warga negara Indonesia atas tanggung jawab Pemerintah dan pemerintah daerah. Namun pada kenyataannya, Kota Mataram sebagai Ibukota Provinsi, mencatat Angka Partisipasi Murni (APK) untuk Sekolah Dasar (SD) sebanyak 93.71, sedangkan penduduk yang buta huruf di Kota Mataram adalah sebanyak 1.30\%.

Pendidikan merupakan hak dasar setiap warga negara. Kewajiban negara untuk mencerdaskan kehidupan rakyat diatur dalam pembukaan UUD 1945. Dengan demikian, pemerintah tidak punya alasan untuk mengabaikan hak setiap warga negara mendapatkan layanan pendidikan. Tapi sampai sekarang rakyat masih sulit mengakses pendidikan itu. Buktinya, angka putus sekolah masih sangat tinggi dan tingkat partisipasi belajar belum mencakup semua usia sekolah. Pada tahun 2013, jumlah SD tidak mengalami perubahan 
berarti dibandingkan tahun 2012. Terjadai penurunan pada jumlah murid SD, sedangkan jumlah TK, SMP dan SMK mengalami peningkatan. Rasio murid sekolah tiap tingkatan pada tahun 2013 adalah 42 (TK), 271 (SD), 338 (SMP), 297 (SMU) dan 315 (SMK) sedangkan rasio murid guru masing-masing 8 (TK), 19 (SD), 15 (SMP), 10 (SMU), dan 12 SMK). Sampai saat ini masih ada 12 juta anak Indonesia yang putus sekolah tiap tahunnya. Di Mataram, Angka Partisipasi Murni (APM) tingkat SD mencapai 97.73, tetapi tingkat APM tingkat SMA hanya 58.79. Itu menggambarkan angka putus sekolah di Kota Mataram masih tinggi. Padahal, ini termasuk barometer nasional. Penyelenggara pendidikan dapat dilihat dari segi program kurikuler serta materi dan jenis pengalaman belajar yang mengisinya, selaras dengan dunia pekerjaan yang akan dimasuki oleh para lulusan. Pendidikan sekolah juga harus dapat mendayagunakan tenaga, dana, fasilitas dan teknologi yang tersedia secara optimal bagi tercapainya tujuan-tujuan pendidikan yang bermutu

Terkait dengan pendidikan yang bermutu yang telah diuraikan di atas Gubernur Nusa Tenggara Barat dalam sebuah pertemuan mengungkapkan dihadapan 500 audiens dari komunitas pendidikan bahwa kemajuan peradaban harus diikuti dengan perbaikan mutu pendidikan. Gubernur menyoroti soal anggaran pendidikan dalam APBD. Meskipun anggaran pendidikan mencapai Rp 286,6 triliun atau hampir setara dengan aturan $20 \%$ APBN, tetapi sebagian besar anggaran itu dipakai untuk membayar gaji dan tunjangan guru.

Ungkapan tersebut mengandung makna bahwa mutu pendidikan di sekolah. Peningkatan sistem pendidikan sebagai sutu hal yang integral yang meliputi input, prosess, output dan outcome secara kesinambungan, pada titik ini adalah suatu keharusan bagi penyelenggara sekolah untuk senantiasa berupaya untuk meningkatkan kinerja, kualitas pelayanan hal ini tentu saja akan bermuara pada upaya peningkatan kualitas pendidikan itu sendiri secara keseluruahan. Karenanya berbagai inovasi yang berorientasi kepada upaya peningkatan kualitas mutu layanan, semestinya menjadi suatu hal mendesak yang perlu diperhatikan oleh segenap pihak yang berkepentingan dengan upaya-upaya peningkatan mutu pendidikan ini. Salah satu unsur pendidikan di sekolah yang memiliki tanggungjawab besar dalam pencapaian tujuan pendidikan adalah kepala sekolah.

Kepala sekolah profesional, yang mau dan mampu melakukan perencanaan, pelaksanaan, serta evaluasi terhadap berbagai kebijakan dan perubahan yang dilakukan secara efektif dan efisien. Sekolah dasar merupakan jenjang pendidikan yang melandasi jenjang pendidikan menengah, merupakan awal dari peserta didik untuk memulai pendidikan formalnya. Kepala sekolah harus lebih memperhatikan keadaan peserta didik, dari masa anak-anak menuju ke arah remaja. Perlu bimbingan dan kesabaran lebih dalam hal psikis, dalam membantu peserta didik mendapatkan informasi tentang beragam pengetahuan.

Kepala Sekolah yang memiliki kinerja baik memang sulit, kepala sekolah harus dapat mendorong tenaga kependidikan untuk berkolaborasi dan bekerjasama dalam meningkatkan kualitas sekolah, serta mewujudkan visi dan misinya. Kepala sekolah dalam pemilihannya pun masih sarat dengan kepentingan politik daripada kompetensi. Sehingga dari awal pengangkatan Kepala Sekolah, budaya yang terbentuk sudah tidak baik.

Kepala sekolah belum sepenuhnya profesional. Sebagai tambahan pula, masih terdapat beberapa kepala sekolah yang masih kurang tanggap terhadap teknologi, berupa masih kurangnya terhadap penguasaan bidang informatika. Dengan kurang maksimalnya kinerja kepala sekolah dasar tersebut, akan menyebabkan budaya organisasi yang tercipta menjadi kurang maksimal.

\section{B. LITERATUR REVIEW \\ 1. Efektivitas Kerja}

Salah satu topik penting dalam mengkaji perilaku manusia adalah kuantitas dan kualitas kerja. Ada tiga istilah penting yang saling terkait erat dalam membahas kuantitas dan kualitas kerja, yaitu efektivitas, efisiensi, dan produktivitas.

Menurut James L.Gibson, James H. Donnelly, JR, John M. Ivancevich, dan Robert Konopaske (2012:15), "managers routinely assess individual effectiveness through performance evaluation process to determine who should receive salary increases, promotions and other reward available in the organization”. Manajer secara rutin menilai efektivitas individu melalui proses evaluasi kinerja untuk menentukan siapa yang harus menerima kenaikan gaji, promosi dan hadiah lain yang tersedia dalam organisasi. Sedangkan menurut Drucker, yang dikutip oleh Laurie J Mullins (2010:475), "the manager is the dynamic, life giving element in every business. Without their leadership the resources of production remain resources and never 
become production. In a competitive economy, above all, the quality and performance of the managers determine the success of a business, indeed they determine its survival. For the quality and performance of its managers is the only effective advantage an enterprise in a competitive economy can have". Manajer adalah dinamis, hidup memberikan elemen dalam setiap bisnis. Tanpa kepemimpinan mereka sumber daya produksi tetap sumber daya dan pernah menjadi produksi. Dalam ekonomi yang kompetitif, di atas semua, kualitas dan kinerja manajer menentukan keberhasilan bisnis, memang mereka menentukan kelangsungan hidupnya. Untuk kualitas dan kinerja manajer adalah satu-satunya keuntungan yang efektif suatu perusahaan dalam ekonomi yang kompetitif dapat memiliki. Lebih lanjut Mullins mengatakan bahwa effektivitas harus memiliki hubungan dengan kesuksesan yang diterima dalam mencakup berbagai tujuan. yang ada pada kinerja dari proses manajemen dan pekerjaan yang sudah ditetapkan dapat tercapai secara nyata.

Menurut Stwewart yang dikutip Laurie J. Mullins (2010:476), "managers who want to improve should review both their effectiveness and their efficiency. Effectiveness is doing the right thing. Efficiency is making the most economic use of the resources. Effectiveness is more important than efficiency because one must be doing the right kind of work. Only then does it matter whether the work is done efficiently".Efektifitas adalah melakukan hal yang benar. Efisiensi adalah membuat penggunaan paling ekonomis dari sumber daya. Efektivitas adalah lebih penting daripada efisiensi karena salah satu harus melakukan jenis pekerjaan yang tepat. Hanya kemudian bedanya apakah pekerjaan dilakukan secara efisien. Manajer dari apa yang telah di lakukannya. Hal senada dikemukakan John R. Schermerhorn, JR (2013:16), "an effective manager help others achieve high performance and satisfaction at work". Efektif manajer membantu orang lain mencapai kinerja tinggi dan kepuasan di tempat kerja.

Dengan demikian dapat disintesiskan efektivitas kerja adalah keberhasilan pegawai dalam melaksanakan tugas untuk mencapai tujuan yang telah ditetapkan organisasi dengan indikator: menyelesaikan pekerjaan tepat waktu, pemanfaatan sumber daya, pencapaian target kerja, pencapaian tujuan.

\section{Budaya Organisasi}

Budaya berkaitan erat dengan persepsi terhadap nilai dan lingkungannya yang melahirkan makna dan pandangan hidup yang akan mempengaruhi sikap dan tingkah laku. Menurut Gareth R. Jones (2013:201), "organizational culture as the set of shared values and norms that control organizational members interactions with each other and with suppliers customers and other people outside the organization". Budaya organisasi sebagai seperangkat nilai-nilai dan norma-norma yang mengendalikan organisasi anggota interaksi satu sama lain bersama dan dengan pelanggan pemasok dan orang lain di luar organisasi. Menurut Robert Kreitner, Angelo Kinicki (2011:64), "organizational culture is the set of shared, taken for granted implicit assumptions that a group holds and that determines how it perceives, thinks about and reacts to its various environment". Budaya organisasi adalah himpunan bersama, diambil untuk asumsi implisit saja bahwa kelompok memegang dan yang menentukan bagaimana ia memandang, berpikir tentang dan bereaksi terhadap berbagai lingkungan.

Menurut Herbert G. Heneman III, Timothy A. Judge, John Kammeyer Mueller (2015:93), "organizational culture is a very complex topic, in part because culture is so difficult to define. in essence, culture is the set of intangibles that influences attitudes and behavior in organizations. some of the factors that can influence an organization culture include the expressed vision of executives, the degree of hierarchy and bureaucracy, the history of interactions among departments and the style of communication throughout the organization". Budaya organisasi adalah topik yang sangat kompleks, sebagian karena budaya sangat sulit untuk menentukan. pada dasarnya, budaya adalah himpunan berwujud yang mempengaruhi sikap dan perilaku dalam organisasi. beberapa faktor yang dapat mempengaruhi budaya organisasi meliputi visi dinyatakan eksekutif, tingkat hirarki dan birokrasi, sejarah interaksi antar departemen dan gaya komunikasi di seluruh organisasi

Menurut John R. Schermerhorn (2013:34) mengatakan bahwa budaya organisasi, "organizational behavior whichis deveted to the study of individuals and groups in organizations". Dapat diartikan perilaku organisasi adalah ilmu khusus untuk mempelajari individu dan kelompok dalam organisasi.

Dari penjelasan di atas dapat disintesiskan budaya organisasi adalah nilai dan norma yang disepakati bersama dan dipegang teguh oleh anggota dalam sebuah organisasi untuk dijadikan panduan melakukan pekerjaannya untuk mendukung pencapaian tujuan organisasinya dengan indikator: aturan atau peraturan yang berlaku, simbol dan bahasa. 


\section{Supervisi}

Supervisi pendidikan merupakan sebuah upaya yang dilakukan untuk meningkatkan mutu pendidikan secara konseptual, yang sesungguhnya sudah lama dikenal dan dibicarakan di lingkungan pendidikan di Indonesia, tetapi nampaknya masih terdapat berbagai ragam pendapat dalam menafsirkan istilah tersebut. Tentunya hal ini akan menimbulkan implikasi yang berbeda pula dalam pelaksanaannya. Rue dan Byars dalam Mukhneri Mukhtar (2011:70) menyatakan, "supervision is the first level management in an organization and is concerned with encouraging the members of a work unit to contribute positively toword accoumplishing the organization's goal and objectives". Supervisi merupakan tingkat pertama dalam sebuah organisasi yang berkaitan dengan bagaimana mendorong anggota suatu unit kerja untuk memberikan kontribusi positif tehadap pencapaian tujuan organisasi secara objektif. Mukhneri Mukhtar mendefinisikan supervisi pendidikan adalah: segala usaha yang dilakukan oleh kepala sekolah dalam rangka memberikan pengarahan, bantuan dan bimbingan kepada guru-guru dalam memperbaiki dan meningkatkan proses belajar mengajar dan korikulum pengajaran di sekolah.

Adapun Laurie J. Mullins (2005:728) mendefinisikan supervisi dengan menyatakan, "supervision involves technical knowledge, human relation skill and coordination of work activities effective supervision is necessary for job satisfaction and high levels of work performance". Supervisi merupakan kegiatan yang melibatkan pengetahuan teknis, keterampilan hubungan manusia dan koordinasi kerja. Supervisi yang efektif diperlukan untuk kepuasan kerja dan tingkat tingi kerja. Sedangkan Hawkins and Shohet (2006:57) berpendapat, "supervision as 'a quintessential interpersonal interaction with the general goal that one person, the supervisor, meets with another, the supervisee, in an effort to make the latter more effective in helping people". Supervisi adalah: "interaksi interpersonal yang dilakukan terhadap perseorangan atau kelompok dengan tujuan membantu mereka menjadi orang yang lebih efektif.

Dari seluruh uraian di atas dapat disintesiskan supervisi adalah aktivitas, bimbingan, pengawasan dan penilaian terhadap pekerjaan seseorang agar menuju ke arah pencapaian tujuan yang telah ditetapkan, dengan indikator-indikator sebagai berikut: (1) pembinaan, (2) bantuan, dan (3) umpan balik.

\section{METODE PENELITIAN}

Penelitian ini menggunakan metode survey dengan teknik korelasi Data penelitian ini dikumpulkan dengan cara memilih sampel dalam populasi. Populasi terjangkau dalam penelitian ini adalah seluruh kepala sekolah SD Negeri di Kota Mataram dalam 3 Kecamatan yang berjumlah 81 Kepala sekolah. Dan perhitungan dengan menggunakan slovin, maka di peroleh jumlah sampel sebanyak 67 kepala sekolah SD Negeri Di Kota mataram yang dijadikan sampel frame dalam penelitian ini. Pengumpulan data digunakan untuk penelitian ini adalah statistika deskriptif dan statistika inferensial.

\section{HASIL PENELITIAN DAN PEMBAHASAN}

\section{Hubungan Budaya Organisasi dengan Efektivitas kerja.}

Hasil pengujian hipotesis pertama dapat disimpulkan bahwa terdapat hubungan positif antara budaya organisasi dengan efektivitas kerja, dimana koefisien korelasi sebesar 0,576 menghasilkan thitung $=5,68$ lebih besar dari ttabel $=2,65$ pada $a=0,01$. Kesimpulan tersebut menunjukkan bahwa semakin tinggi budaya organisasi, maka akan semakin tinggi pula efektivitas kerja.

Korelasi antara budaya organisasi dengan efektivitas kerja menunjukkan kebermaknaannya, baik melalui korelasi product moment maupun korelasi parsial. Hasil analisis ini memberikan petunjuk bahwa budaya organisasi merupakan salah satu faktor utama yang berkonstribusi terhadap efektivitas kerja. Dari hasil itu pula dapat diinterpretasikan bahwa peningkatan budaya organisasi akan memberikan konstribusi yang berarti terhadap efektivitas kerja. Hal ini sesuai dengan pendapat Herbert G. Heneman III, Timothy A. Judge, John Kammeyer Mueller (2015:93), "organizational culture is a very complex topic, in part because culture is so difficult to define. in essence, culture is the set of intangibles that influences attitudes and behavior in organizations. some of the factors that can influence an organization culture include the expressed vision of executives, the degree of 
hierarchy and bureaucracy, the history of interactions among departments and the style of communication throughout the organization". Budaya organisasi adalah topik yang sangat kompleks, sebagian karena budaya sangat sulit untuk menentukan. pada dasarnya, budaya adalah himpunan berwujud yang mempengaruhi sikap dan perilaku dalam organisasi. beberapa faktor yang dapat mempengaruhi budaya organisasi meliputi visi dinyatakan eksekutif, tingkat hirarki dan birokrasi, sejarah interaksi antar departemen dan gaya komunikasi di seluruh organisasi. Supervisi adalah bagian dari usaha seseorang pimpinan untuk mengawasi kinerja bawahannya. Dan budaya merupakan salah satu bagian yang cukup penting ketika akan melakukan supervisi. Kita harus mengenal siapa dan dimana kita melakukan supervisi.

\section{Hubungan Supervisi dengan Efektivitas Kerja.}

Hasil pengujian hipotesis kedua dapat disimpulkan bahwa terdapat hubungan positif antara supervisi dengan efektivitas kerja, dimana koefisien korelasi sebesar 0,552 menghasilkan thitung $=5,33$ lebih besar dari tabel $=2,65$ pada $\alpha=0,01$. Kesimpulan tersebut menunjukkan bahwa semakin tinggi supervisi, maka akan semakin tinggi pula efektivitas kerja.

Korelasi antara supervisi dengan efektivitas kerja menunjukkan kebermaknaannya, baik melalui korelasi product moment maupun korelasi parsial. Hasil analisis ini memberikan petunjuk bahwa supervisi merupakan salah satu faktor utama yang berkonstribusi terhadap efektivitas kerja. Dari hasil itu pula dapat diinterpretasikan bahwa peningkatan supervisi akan memberikan konstribusi yang berarti terhadap efektivitas kerja. Hal ini sesuai dengan pendapat Lesrie W. Rue, Lioyd L. Bays (2010:3), "supervise is the level of management in an organization an is concerned with encouraging the members of a work unit to contribute positively toward accomplishing the organization's goal and objectives". Supervisi adalah tingkat pertama dari manajemen dalam suatu organisasi yaitu dengan mendorong anggota organisasi untuk memberikan kontribusi positif dalam mencapai tujuan organisasi. Manajemen yang baik tentunya berdampak pada kerja kepala sekolah yang efektif, dimana kepala sekolah mampu untuk memilih ujuannya tepat untuk mencapai tujuan yang telah di tetapkan.

Menurut James L.Gibson, James H. Donnelly, JR, John M. Ivancevich, Robert Konopaske (2012:15), "managers routinely assess individual effectiveness through performance evaluation process to determine who should receive salary increases, promotions and other reward available in the organization". Manajer secara rutin menilai efektivitas individu melalui proses evaluasi kinerja untuk menentukan siapa yang harus menerima kenaikan gaji, promosi dan hadiah lain yang tersedia dalam organisasi. Kepala sekolah yang mampu melaksanakan pekerjaan dengan efektif akan berhasil membawa sekolah ke arah yang lebih baik pula. Ditambah dengan dukungan kemampuan budaya organisasi yang baik akan menambah peningkatan mutu sekolah. Apabila dalam pelaksanaan supervisi dapat berjalan dengan optimal maka kepala sekolah sebagai pemimpin organisasi sekolah dapat bekerja secara efektif. Semakin optimal pelaksaan supervisi maka semakin tinggi efektivitas kerja sebaliknya semakin tidakoptimal supervisi maka semakin rendah efektivitas kerja kepala sekolah.

\section{Hubungan antara budaya organisasi dan supervise Secara Bersama-sama \\ dengan efektivitas supervisi.}

Hasil pengujian hipotesis ketiga dapat disimpulkan bahwa budaya organisasi dan supervisi secara bersama-sama mempunyai hubungan positif dengan efektivitas kerja. Koefisien korelasi ganda antara kedua variabel bebas dengan variabel terikat $R_{y .12}$ sebesar 0,809 meghasilkan $F_{\text {hitung }}=60,49$ lebih besar dari $F_{\text {tabel }}=4,95$ pada $\quad \alpha=0,01$. Dari koefisien korelasi tersebut, dapat dihitung koefisien determinasi $\left(\mathrm{R}_{\mathrm{y} .12}\right)^{2}$ sebesar 0,6541 berarti bahwa $65,41 \%$ proporsi varians efektivitas kerja dapat dijelaskan secara bersama-sama oleh budaya organisasi serta supervisi. Hal ini sesuai dengan pendapatCarlene Cassidy, Robert kreitner (2010:5), "supervisor are an integral part of the management team process. The legal definition of supervisor is any individual having authority, in the interest of employer to hire, transfer, suspend lay off, recall, promote, discharge, assign, reward or discipline other employees or responsibly to direct them, or to adjust their grievances, or effectively to recommend such action, if in connection with the foregoing the exercise of such authorithy is not of merely routine or clerical nature, but requires the use of independent judgement". Pengawasan merupakan bagian integral dari proses manajemen tim, definisi hokum pengawasan yang memiliki wewenang adalh setiap individu, dalam kepentingan pimpinan, untuk menyewa, mentransfer, 
menangguhkan, memberhentikan, ingat, mempromosikan, menentapkan, penghargaan atau untuk pegawai yang disiplin atau bertanggung jawab untuk mengarahkan mereka atau untuk menyesuaikan keluhan mereka. Atau secara efektif untuk merekomendasikan tindakan tersebut, jika sehubungan dengan hal tersebut pada pelaksanaan kewenagan tersebut tidak semata-mata dilakukan secara rutin atau alami, tetapi membutuhkan penggunaan penilaian yang independen.

\section{E. KESIMPULAN}

Kesimpulan: (1) Budaya organisasi berhubungan positif dengan efektivitas kerja. Artinya, semakin kondusif budaya organisasi, maka semakin meningkat efektivitas kerja kepala sekolah. (2) Supervisi berhubungan positif dengan efektivitas kerja. Artinya, semakin baik supervisi yang dilakukan kepala sekolah, maka semakin meningkat efektivitas kerja kepala sekolah. (3) Budaya organisasi dan supervisi secara bersama-sama berhubungan positif dengan efektivitas kerja. Artinya, semakin kondusif budaya organisasi dan semakin efektif supervise secara bersama-sama, maka semakin meningkat efektivitas kerja kepala sekolah. Saran (1) Bagi kepala Dinas Pendidikan Kota Mataram untuk membantu meningkatkan upaya kepala sekolah untuk memperbaiki budaya organisasi yang ada di sekolah agar tercipta budaya organisasi yang kondusif untuk proses pembelajaran dan memberikan penyuluhan kepada kepala sekolah dalam rangka melakukan supervise yang baik dan seusai juknis yang sudah ditetapkan. (2) Bagi kepala sekolah untuk terus memperbaiki budaya organisasi yang sudah ada menuju lebih baik dan melakukan update cara melakukan supervisi yang baik dengan tujuan secara maksimal. (3) Bagi peneliti lain, dapat dijadikan bahan rujukan dalam rangka peneliti lebih lanjut terkait dengan budaya organisasi dan supervisi dengan efektivitas kerja.

\section{F. DAFTAR PUSTAKA}

1. Certo, Samuel C., S. Trevis Certo, Modern Management concept and skills 13 edition. England: Pearson,2014.

2. Colquitt, Jason A. Organizational Behavior Improving Performance and Commitment in The Workplace 4 th Edition. New York: Mc Graw Hill, 2015.

3. Daft, Richard L., Dorothy Marcic, Understanding management 9 edition. USA: Cengange Learning, 2015.

4. Gibson, James L., James H. Donnelly, John M. Ivancevich, Robert Konopaske, oganizations: behavior structure processes 14 edition . New York: McGraw Hill, 2012.

5. Hawkins, Peter and Robin Shohet, Supervision in the helping Professions, New York, McGraw-Hill Open University Press.2006.

6. Hawkins, Peter, Robin Shohet,supervision in the helping professions 3 edition. New York: McGrawHill, 2006.

7. Heneman III, Herbert G. Timothy A. Judge, John Kammeyer Mueller, Staffing Organizations 8 edition. New York: Mc Graw Hill, 2015.

8. Ivancevich, John M. Human Resource Management, Tenth Edition, New York: McGraw-Hill, 2007.

9. Jones, Gareth R., Organizational Theory, Design and Change 7 Edition. England:Pearson, 2013.

10. Kinicki, Angelo, Brian Williams, Management a Practical Introduction. New York: Mc Graw Hill, 2011.

11. Kreitner, Robert, Angelo Kinicki, Organizational Behavior 9 Edition. New York: Mc Graw Hill, 2011.

12. Schermerhorn, John R., Jr. Introduction to Management 12 edition. Asia :John Wiley \& Sons,Inc. 2013. 